Article

\title{
Towards Self-Powered WSN: The Design of Ultra-Low-Power Wireless Sensor Transmission Unit Based on Indoor Solar En- ergy Harvester
}

\author{
Fathi Mahdi Elsiddig Haroun ${ }^{1,}{ }^{*}$, Siti Noratiqah Mohamed Deros ${ }^{1}$, Ammar Ahmed Alkahtani ${ }^{2}$, and Norashidah \\ Md Din ${ }^{1}$
}

1 Institute of Energy Infrastructure, Universiti Tenaga Nasional, Kajang 43000, Malaysia; siti.noratiqah@uniten.edu.my (S.N.M.D); norashidah@uniten.edu.my (N.M.D)

2 Institute of Sustainable Energy, Universiti Tenaga Nasional, Kajang 43000, Malaysia; ammar@uniten.edu.my (AAA)

* Correspondence: fathi.mahdi@uniten.edu.my

\begin{abstract}
The current revolution in communication and information technology is facilitating the Internet of Things (IoT) infrastructure. Wireless Sensor Networks (WSN) are a broad category of IoT applications. However, power management in WSN poses a significant challenge when the WSN is required to operate for a long duration without the presence of a consistent power source. In this paper, we develop a batteryless, ultra-low-power Wireless Sensor Transmission Unit (WSTx) depending on the solar-energy harvester and LoRa technology. We investigate the feasibility of harvesting ambient indoor light using polycrystalline photovoltaic (PV) cells with a maximum power of $1.4 \mathrm{~mW}$. The study provides comprehensive power management design details and a description of the anticipated challenges. The power consumption of the developed WSTx was $21.09 \mu \mathrm{W}$ during the sleep mode and $11.1 \mathrm{~mW}$ during the operation mode. The harvesting system can harvest energy up to $1.2 \mathrm{~mW}$ per second, where the harvested energy can power the WSTx for six hours with a maximum power efficiency of $85.714 \%$.
\end{abstract}

Keywords: Energy harvester, LoRa, solar power, ultra-low power, WSN

\section{Introduction}

The revolution in the microchips industry, especially in microcontrollers (MCUs), helped integrate embedded systems with various types of daily used devices. The demand to connect these devices to the internet became vital due to the emerging technologies in information and communication infrastructure such as high-speed internet, cloud computing, and big data. The Internet of Things (IoT) technology enables machines such as home appliances, medical equipment, and industrial instruments to interact with users and other machines through the internet [1, 2]. Portable, Wireless Sensor Network (WSN) represents a broad IoT application sector [3]. The role of WSN in IoT applications is to convert and transfer environmental variables such as temperature, pressure, vibration, and other variables through a wireless network of devices. This network can send and receive data from the internet through a gateway node [3, 4]. The WSN system usually consists of four main units: sensing unit, processing unit, wireless communication unit, and power management unit, as shown in Figure 1 [5]. Power management in WSN devices is always a challenging issue. Such devices are required to operate in remote locations for several years without charging or replacing the storage element, compared with other battery-powered devices like mobile phones $[6,7]$. Battery management techniques, low power MCUs and low power communication technologies are required to mitigate the power consumption in WSN systems. The new emerging Long-Range (LoRa), lowenergy consumption radio modulation technology enables wireless sensor devices to communicate through a low-power consumption profile, compared with other widely 
used wireless communication technologies like ZigBee, Bluetooth, Wi-fi, and cellular communication bands [7-9].

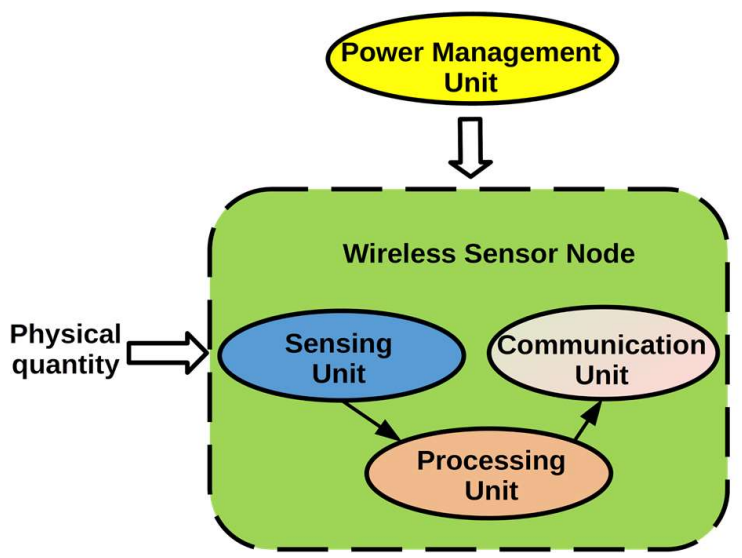

Figure 1. The main elements of the WSN.

Due to modulation bandwidth limitations, LoRa technology can only be used be used for low data transfer rate applications [10-12]. Figure 2 shows a comparison between different wireless communication technologies in terms of data transfer rate, coverage range, and power consumption.

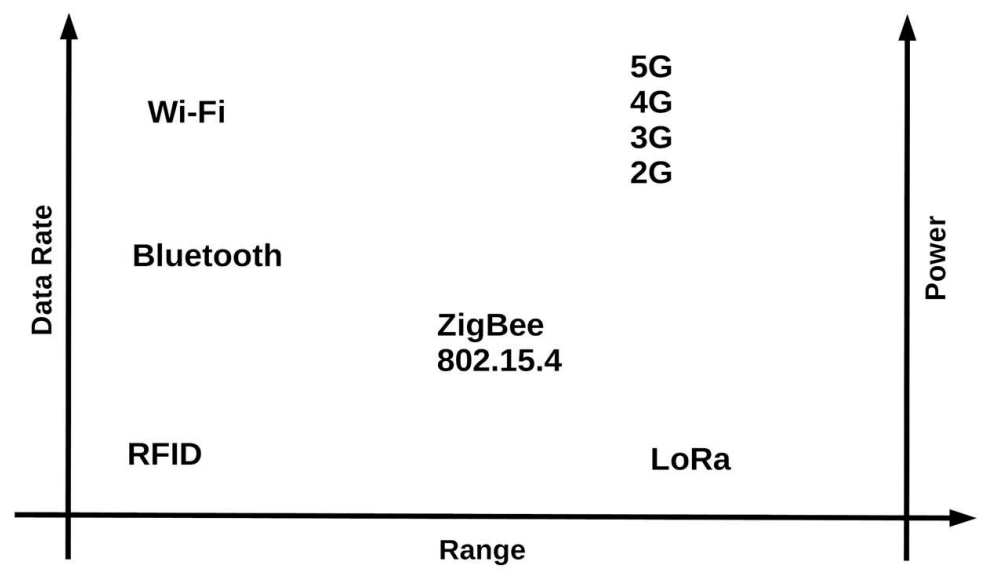

Figure 2. Comparison between commonly used wireless communication technologies regarding data transfer rate, coverage range, and power consumption.

Aside from the low power communication technology, energy harvesters play a significant role in WSN power sustainability [13-15]. Energy harvesters can be used to harvest the abundant energies from the environment to power IoT devices. Thermal, wind, radio wave, solar, and piezoelectrics energy are examples of such sources [15]. Figure 3 illustrates the concept of energy harvesters in the IoT field. Solar energy is the most widely used type of renewable energy due to its efficiency in converting solar irradiance into electricity when compared to other types of renewable technologies [16]. The PV cells heavily depend on the light intensity to produce electrical energy. However, some IoT applications require an indoor hosting environment. Indoor environments use artificial light sources such as compact fluorescent lamps and LEDs. These devices have a low light intensity compared to sunlight; therefore, the indoor environment poses a challenge to PV cells. Power management strategies are important in reducing power consumption in such a low energy situation. This paper provides a comprehensive study on designing an Ultra-Low-Power (ULP) LoRa-based Wireless Sensor Transmission unit (WSTx) based on indoor solar cells. 


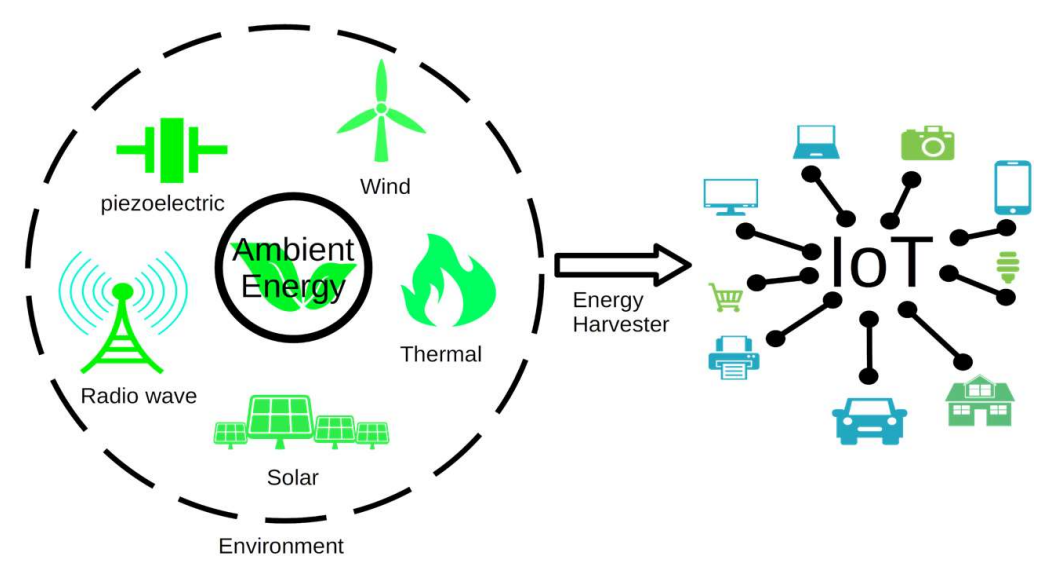

Figure 3. The Utilization of the ambient energy in IoT applications.

\section{Materials and Methods}

The study is on the design of self-powered WSTx that can harvest the ambient light from indoor PV cells. The proposed scheme of the ULP WSN system is composed of two main units, the Power Management Unit (PMU) and the WSTx. The PMU has three main elements: a Maximum Power Point Tracking (MPPT) circuit, a buck-boost converter, and a battery charger. The purpose of the PMU is to provide stable and efficient charging and discharging rates to the storage element considering the load from the WSTx. On the other hand, the WSTx consists of three main elements: an MCU, a sensor module, and a communication module, as shown in Figure 4. The purpose of the WSTx is to encode and transfer the sensor data through the communication module.

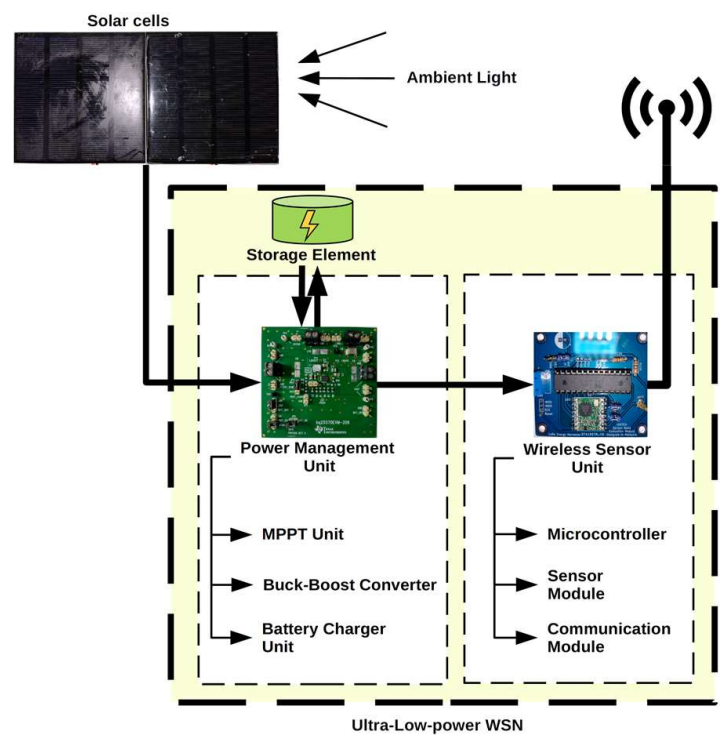

Figure 4. The proposed Ultra-Low-power WSTx system diagram

\subsection{Study Area}

The study has been conducted in the University Tenaga Nasional, Energy Sphere IoT lab. The lab has a $6.5 \times 9.5$ square meter area consisting of 24 LED ceiling lamps. Each LED has a maximum luminous of 6600 lux, as shown in Figure 5. The LED ceiling lamps are gradually becoming the dominant light source in streets, offices, and workspaces due to their power efficiency compared with fluorescent lamps [17, 18]. 


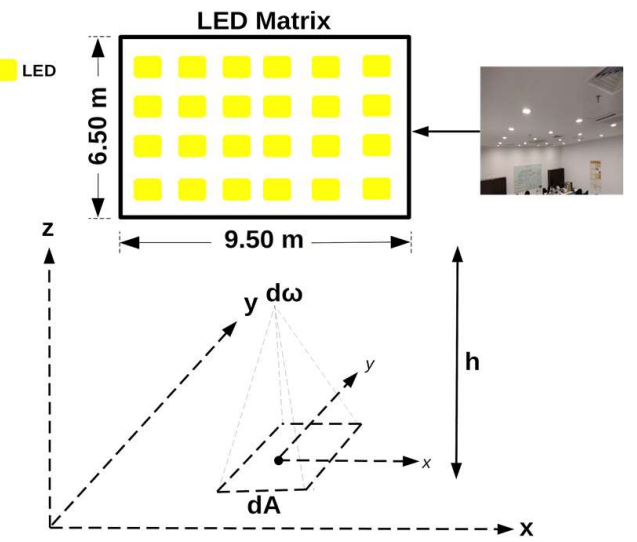

Figure 5. Illustration of the study area, where there are 24 LED ceiling lamps each LED has a maximum luminance of 6600 lux

The main concern about artificial light is the amount of light intensity with respect to the surface of the observer. The intensity of the LED follows the Lampartian principle $[19,20]$, where the degree of illuminance varies according to the cosine angle of the observer. The light intensity of a white LED can be represented using the Gaussian distribution function $f_{\theta}(\theta)$ as in (1) [20-22]. The light intensity varied according to the angular displacement $\theta$ as in Figure 6, where $\theta$ is bounded by a minimum of -90 degrees and a maximum of 90 degrees. The maximum intensity can be obtained at the mean value $\sigma$ of the Gaussian distribution. The illuminance intensity $I_{r}$ of any light source describes the amount of luminous flux $\varphi$ at angle $\omega$ as shown in Figure 5, where the illuminance intensity can be calculated as in (2) [19]. Therefore, the illuminance intensity of the LED decreases as the height $h$ from the light source increases, as illustrated in Figure 7.

$$
\begin{gathered}
f_{\theta}(\theta)=\left(\frac{\mathrm{k}}{\sigma \sqrt{\frac{\pi}{2}}}\right) \mathrm{e}^{-2\left(\frac{\theta-\mu}{\sigma}\right)^{2}},(-90 \leq \theta \leq 90) \\
\mathrm{d} \varphi=\left(I_{r} / h^{2}\right) \cos (\theta) d A, d \omega=\left(d A / h^{2}\right) \cos (\theta), \\
I_{r}=\frac{\mathrm{d} \varphi}{d \omega}=\frac{\left(I_{r} / h^{2}\right) \cos (\theta) d A}{\left(d A / h^{2}\right) \cos (\theta)}
\end{gathered}
$$

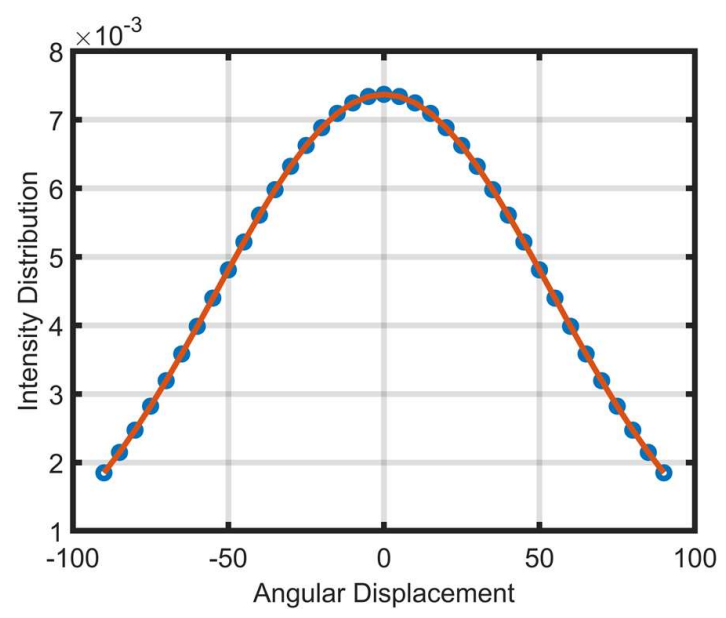

Figure 6. LED light intensity distribution $(\mu=0, \sigma=54.1218)$. 


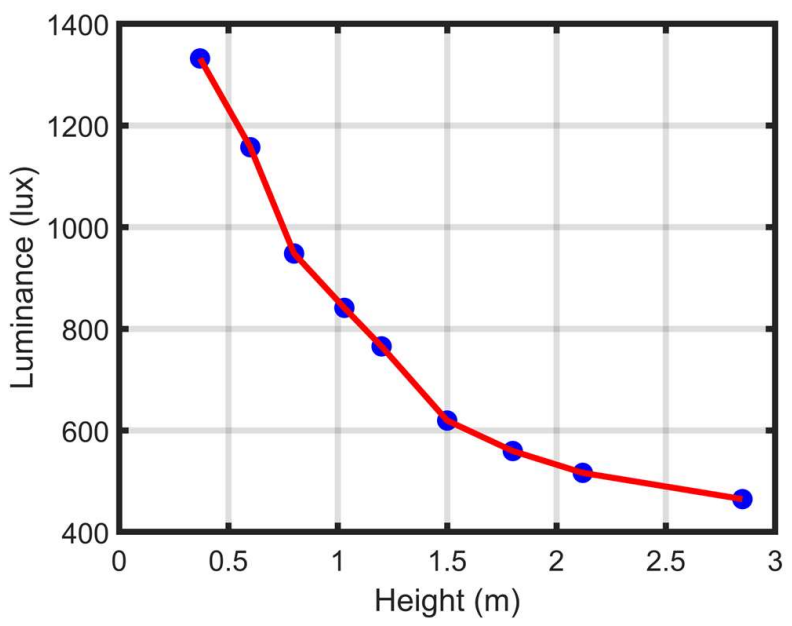

Figure 7. The relation between luminance and the height

The illuminance intensity formula can be converted into the cartesian coordination where the illuminance at any point $P(x, y, z)$ can be obtained as in (3) where $(\mathrm{X}, \mathrm{Y}, \mathrm{Z})$ represent the global coordination with respect to the light source. The equation to obtain the total illuminance from the LED matrix at any point in the surface can be represented in (4) [23].

$$
\begin{gathered}
\mathrm{E}(x, y, z)=\frac{z I_{r}}{\left(X^{2}, Y^{2}, Z^{2}\right)^{-2 \ln (2) / \ln (\cos (\theta))}} \\
\sum_{i=1}^{24} \mathrm{E}_{i}(x, y, z)=\sum_{i=1}^{24} \frac{z I_{r}}{\left((x-X)^{2},(y-Y)^{2},(z)^{2}\right)^{-2 \ln (2) / \ln (\cos (\theta))}}
\end{gathered}
$$

\subsection{PV cells}

The basic principle behind the PV effect has emerged from semiconductor technology, where the conductivity status of semiconductor materials such as silicon can be determined by adding impurities. The impurities convert the pure semiconductor material into major and minor electron carriers, representing a positive P-channel region or a negative $\mathrm{N}$-channel region [24]. The silicon PV cell is constructed from a PN-junction where a thin $\mathrm{N}$-channel is used to absorb the light allowing the photons to reach the P-channel. If the photon has sufficient energy to hit the bond of the silicon crystal, an electron pair of positive holes and negative electrons will be generated, as illustrated in Figure 8. This process will cause a voltage difference between the N-channel and the P-channel, which by its role will drive the electrical current to flow through the depletion layer $[25,26]$.

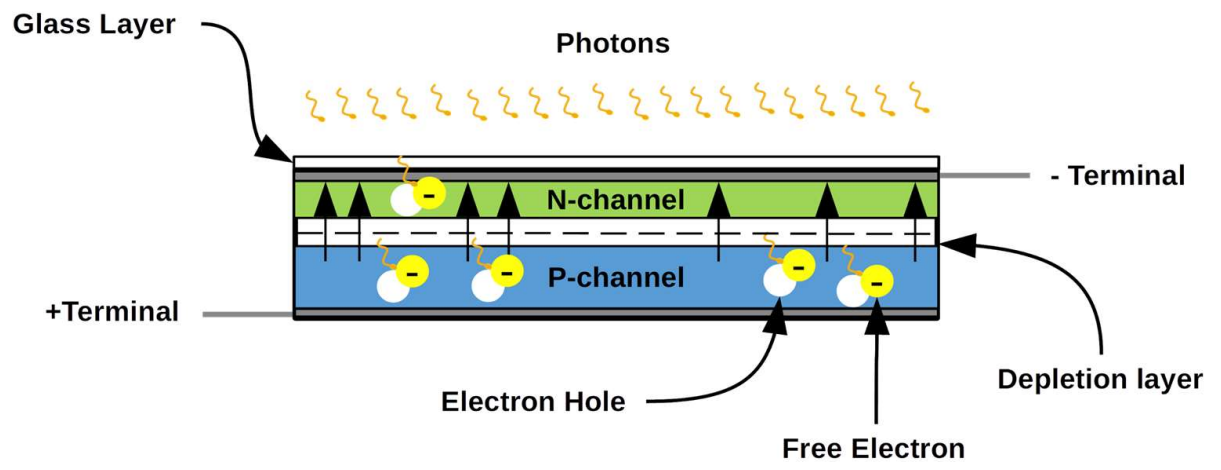

Figure 8. The internal structure of a silicon solar cell. 


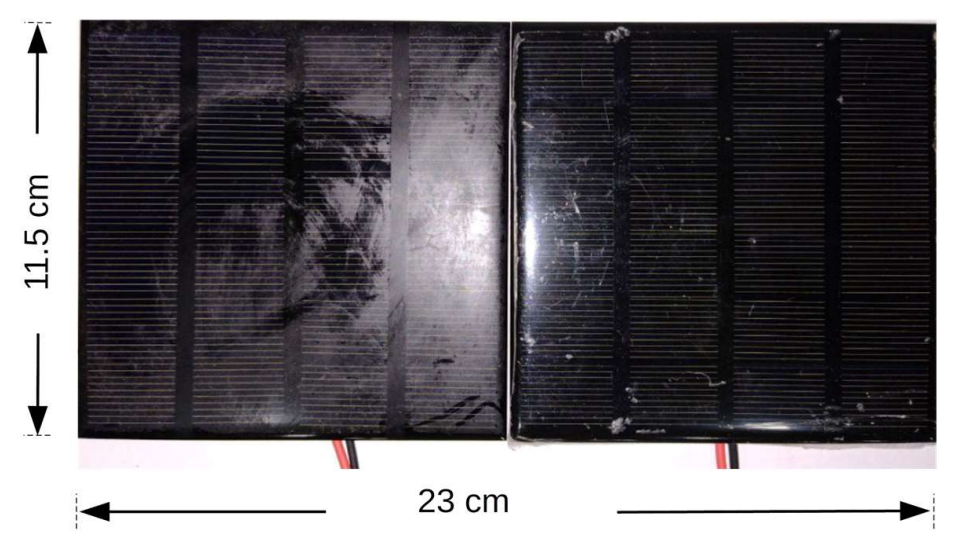

Figure 9. An $11.5 \times 23 \mathrm{~cm}^{2}$ polycrystalline solar panels

Polycrystalline (P-c) and Monocrystalline (M-c) solar cells are the most commonly used types of silicon PV [27]. P-c solar cells are synthesized from several silicon crystals. The efficiency of the P-c solar cells can reach $13 \%$. On the contrary, M-c solar cells are synthesized from a single silicon crystal. The M-c silicon cells have higher efficiency than the P-c cells, which can reach 15\% [28]. However, the prices of M-c cells are much higher than P-c cells. Besides the silicon-based solar cells, the PV effect can be obtained from different non-silicon materials such as organic solar cells, perovskite solar cells, and dyesensitized solar cells [29-31]. In this study, two P-c solar panels have been used to collect the ambient light from the indoor environment. The solar panels have a total area of $11.5 \times 23.0$ square centimeters, as shown in Figure 9. The light intensity in the study area varies according to the height from the light source. The closer the distance to the light source, the higher the luminance intensity; hence, the generated voltage is proportional to the luminance intensity, as shown in Figure 10.

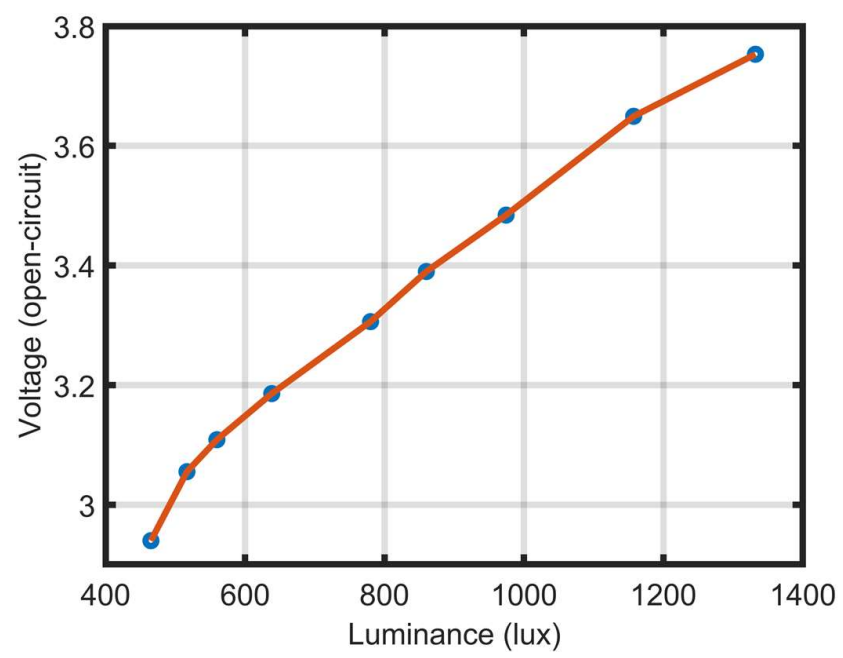

Figure10. The relation between the luminance and the generated open-circuit voltage.

The panels have been connected in a parallel configuration to maximize the output current. The outdoor and indoor performance of the panels is shown in Figure 11. The Figure describes the non-linear relation between current and voltage, known as the IV curve. The MPP is the result of direct multiplication of the maximum current $I_{M p p}$ times the maximum voltage $V_{M p p}$, as in (5). The outdoor Maximum Power Point (MPP) value was $1.76 \mathrm{~W}$, and in contrast, the indoor MPP was $1.4 \mathrm{~mW}$. The modelling of PV cells is significant to study the efficiency of solar panels. There are two common models for solar cells: the one-diode model and the two-diode model [32]. Both models can represent the sollar cell, whereas, in this study, we used the one-diode representation as in Figure 12. 


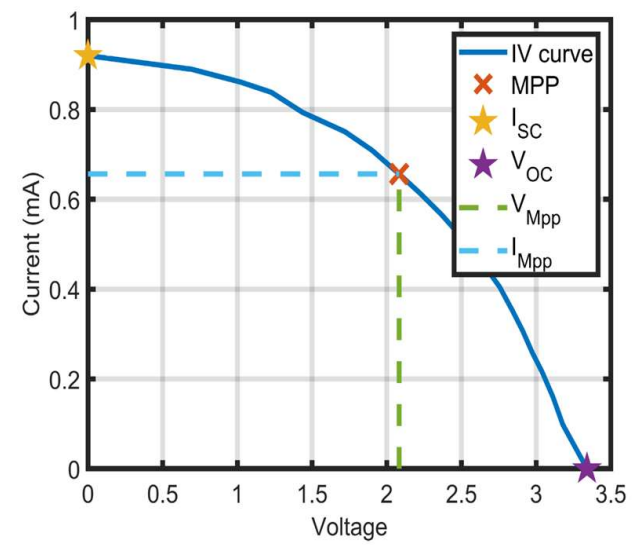

(a)

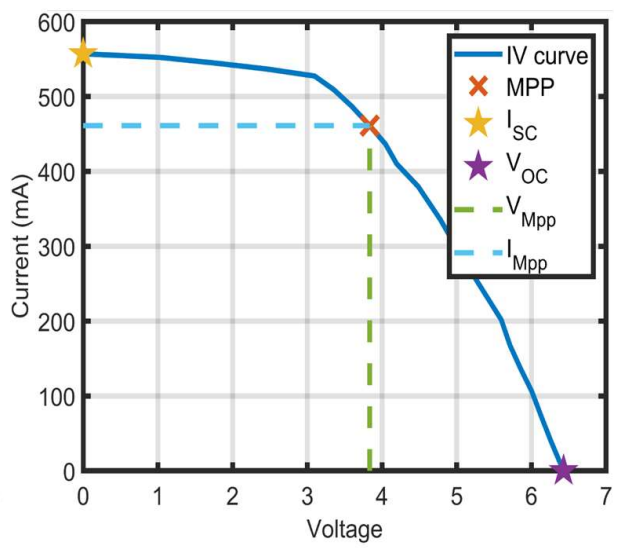

(b)

Figure 11. solar panel performance; (a) is the indoor I-V characteristic curve, and (b) is the outdoor I-V characteristic curve

The one-diode model describes the parameters of the solar cells where $i_{P h}$ represents the source photon current generated by the PV effect. The total net current $i_{P v}$ can be calculated as in (6) where $I_{0}$ is the reverse saturation current, $I_{s h}$ is the shunt current, T is the absolute temperature, $\mathrm{q}$ is the charge of the electron, $\mathrm{k}$ is the Boltzmann constant, $R_{S}$ is the shunt resistor, $v_{P v}$ is the voltage difference across the PV cell terminals, and $\alpha$ is the diode factor $[33,34]$. The efficiency of the solar cell $\eta$ is related to the ratio between the input power and the maximum output power. The input power in the outdoor situation is the solar irradiance $(1000 \mathrm{w} / \mathrm{m} 2)$; hence the total size of the solar panel is $\left(11.65 \times 23 \mathrm{~cm}^{2}\right)$ the outdoor efficiency of the P-c solar panels can be estimated as in (8) where FF is the fill factor as in (7).

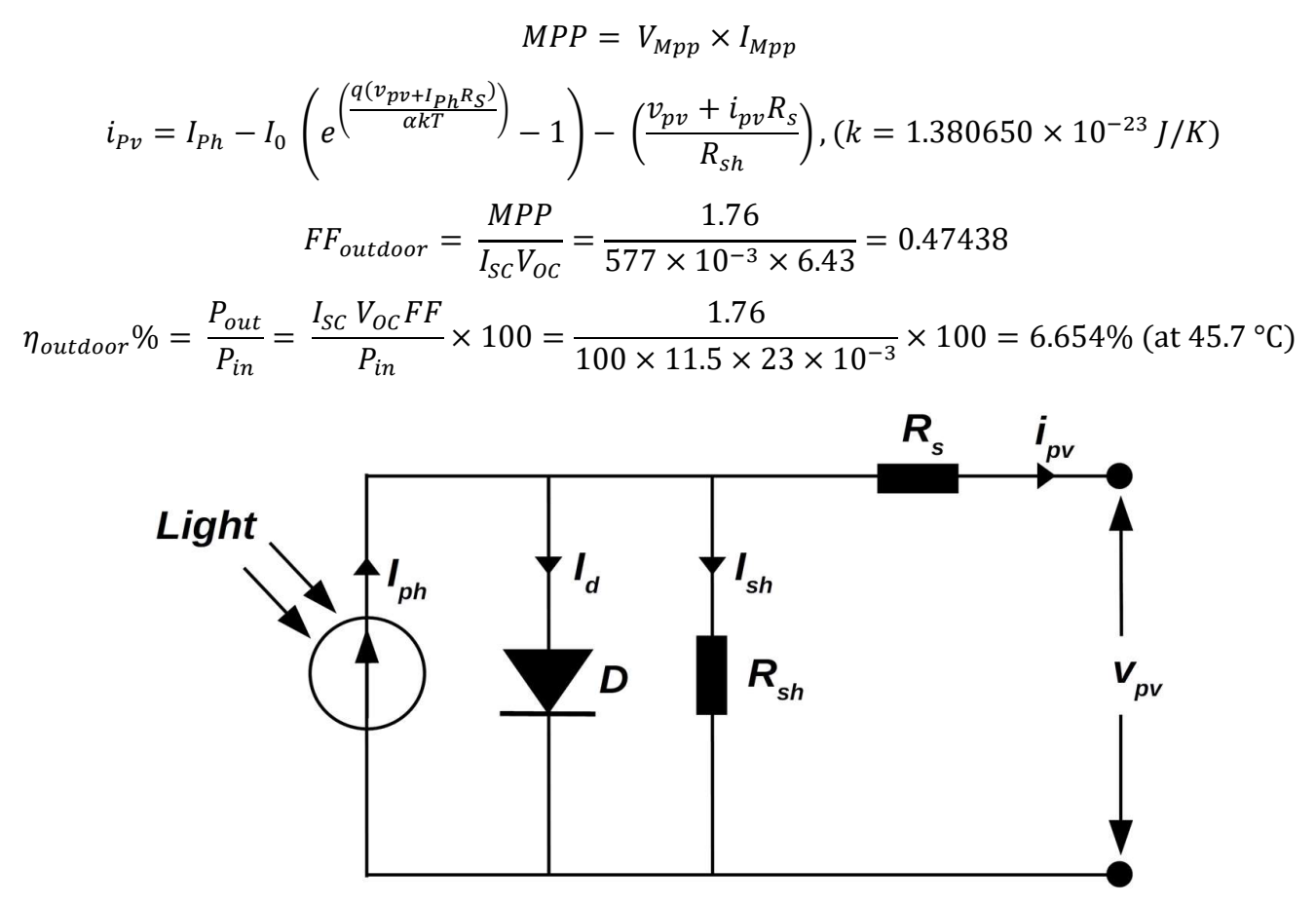

Figure 12. The one-diode model solar cell equivalent circuit.

According to P. R.Michael et al [35], for an indoor environment with LED light, the conversation between irradiance and luminance can be estimated as in (9); therefore, the 
indoor efficiency of the solar panels can be calculated as in (11). Table 1 compares the indoor and outdoor parameters of the solar panels.

$$
\begin{aligned}
& 1\left(\mathrm{~W} / \mathrm{m}^{2}\right)=116 \pm 3 \operatorname{lux} \text { (indoor) } \\
& \therefore \text { at } 582 \text { lux }=0.50172\left(\mathrm{~mW} / \mathrm{cm}^{2}\right) \pm 0.02 \\
& F F_{\text {indoor }}=\frac{M P P}{I_{S C} V_{O C}}=\frac{0.0014}{0.98 \times 10^{-3} \times 3.34}=0.42772 \\
& \eta_{\text {indoor }} \%=\frac{P_{\text {out }}}{P_{\text {in }}}=\frac{I_{S C} V_{\text {OC }} F F}{P_{\text {in }}} \times 100=\frac{1.400 \times 10^{-3}}{0.50172 \times 11.5 \times 23 \times 10^{-3}} \times 100=1.055 \% \pm 0.045\left(\text { at } 25^{\circ} \mathrm{C}\right)
\end{aligned}
$$

Table 1. Comparison between indoor and outdoor parameters.

\begin{tabular}{cccccccc}
\hline & $\operatorname{Temp}\left({ }^{\circ} \mathrm{C}\right)$ & $\mathrm{Isc}(\mathbf{m A})$ & Voc & VMPP & IMPP(mA) & MPP (mW) & $\boldsymbol{\eta} \%$ \\
\hline Indoor & 25 & 0.98 & 3.34 & 1.977 & 0.707 & 1.4 & $1.055 \pm 0.045$ \\
Outdoor & 45.7 & 577 & 6.43 & 3.88 & 453.4 & 1760 & 6.654 \\
\hline
\end{tabular}

\subsection{Power Management Unit}

The PMU is essential for IoT applications that work without a consistent power supply [36-38]. In this study, the Texas Instrument bq25570 energy management module [39] has been used to manage the harvested solar power. The module is mainly designed for ULP applications where it provides an efficient power extraction from low power, highinput impedance generators such as solar cells. The module's operation starts by converting the input voltage into higher voltage levels through an embedded DC to DC boost converter. The converter can operate at a low starting input voltage of $330 \mathrm{mV}$; once the voltage at the boost charger $V_{S T O R}$ terminal reaches $1.8 \mathrm{~V}$; the converter will accept lower voltages as $120 \mathrm{mV}$. The efficiency of the boost converter depends on the amount of power reaching the storage element concerning the input power as in (12). Figure 13 shows the efficiency curve of the boost charger concerning the input voltage. Besides this, the module offers a programable MPPT unit that enables extracting the maximum power under various ambient light conditions. Also, the module can maintain a stable output voltage through the embedded buck converter, which can deliver up to $100 \mathrm{~mA}$ to the buck converter output terminal. Figure 14 shows the bq25570 module and the connection terminals.

$$
\eta \%=\frac{P_{\text {out }}}{P_{\text {in }}}=\frac{V_{S T O R} \times I_{S T O R}}{V_{I N} \times I_{I N}}
$$

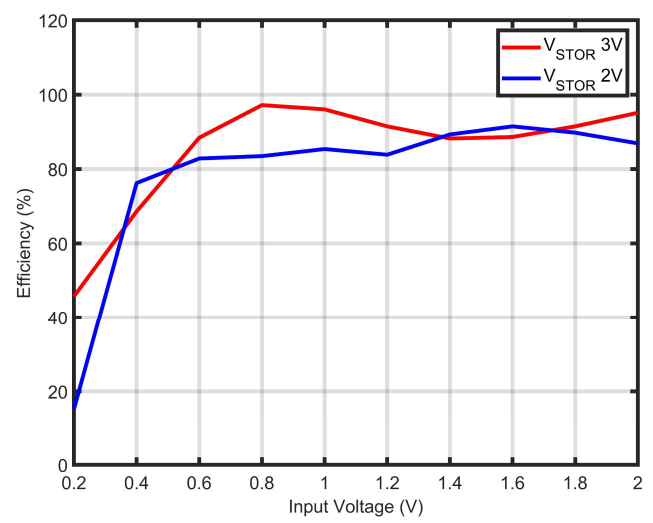

Figure 13. Boost converter efficiency curve $\left(I_{I N}=0.656 \mathrm{~mA}\right)$ 


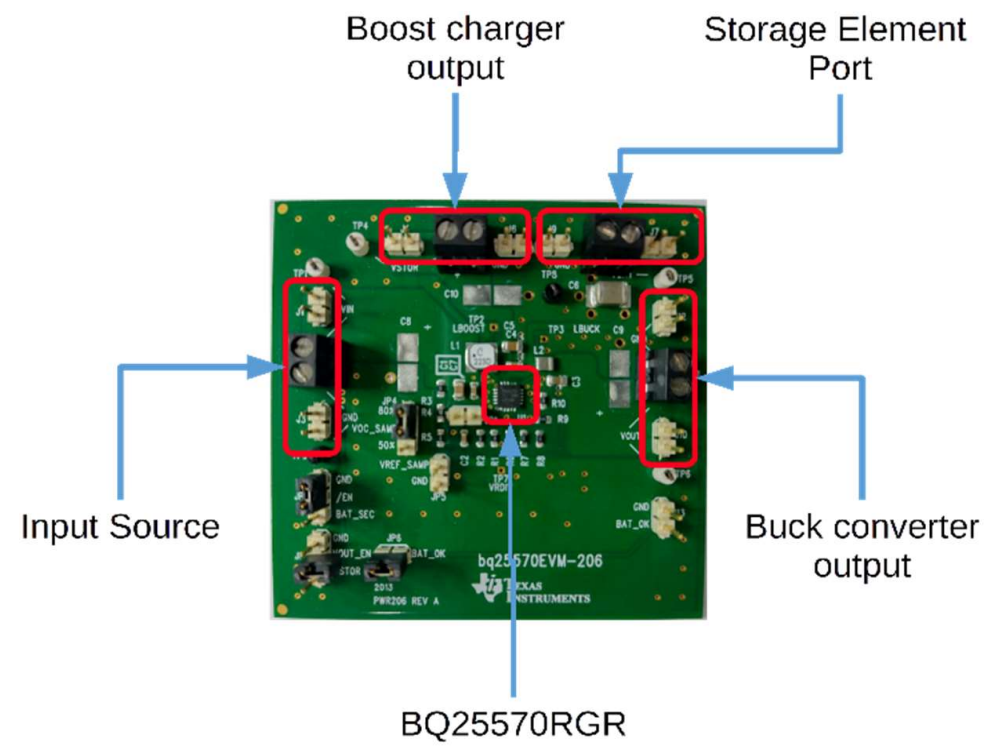

Figure 14. The bq25570 power management module

There are many types of rechargeable batteries that can be used to store the harvested voltage, such as lithium-ion (Li-ion) and Lithium-ion Polymer (LiPo) batteries. However, these types of storage elements have a high Equivalent Series Resistance (ESR) and a short cycle-life $[40,41]$. The supercapacitor can be used alternative to batteries in energy harvesting applications [42-44]. The supercapacitors have low ESR, which provides a fast peak power delivery. Also, supercapacitors have a long cycle-life compared with Li-ion batteries. In this study, we used a $90 \mathrm{~F}$ supercapacitor with a maximum charging voltage of $4.2 \mathrm{~V}$ to store the harvested solar power. Figure 15 shows the open-circuit supercapacitor charging curve through the PMU.

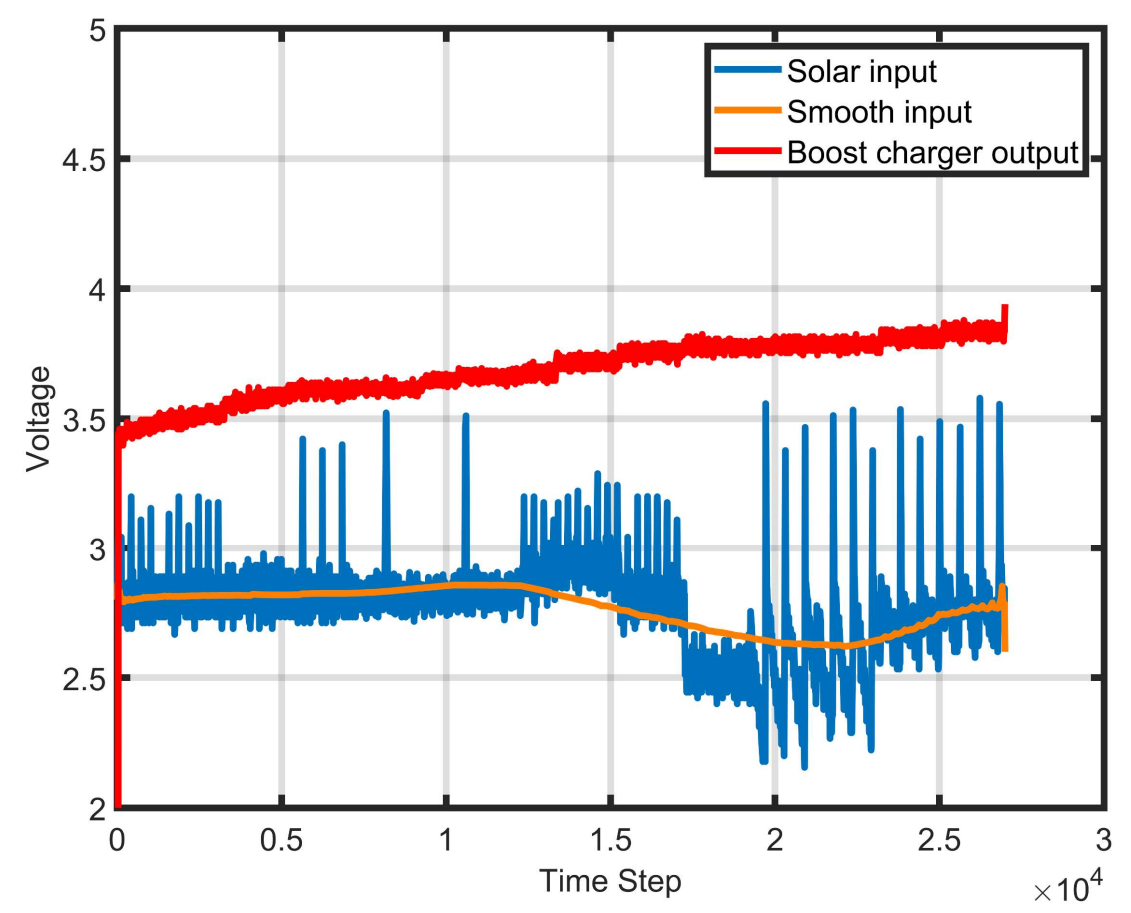

Figure 15. Supercapacitor charging curve versus the solar input voltage (at 582 lux).

\subsection{Wireless Sensor Unit}


The wireless sensor unit consists of three main components, the DHT11 humidity and temperature sensor, the ATMEGA328P MCU, and the RFM96W LoRa module $[45,46]$ as shown in Figure16, more design details can be found in APPENDIX A. Table 2 describes the current and voltage characteristics of the WSTx components. The MCU can manage the control signals and the communication protocols; hence, the MCU is the key element of reducing the power consumption from the WStx. Many studies have been published about reducing MCU power consumption. For instance, Amit Sinha et al. [47] proposed an Operating System (OS) based dynamic power management of WSN. The authors proposed event-driven power management to reduce the power consumption where the OS can automatically determine the operation mode of the MCU. Also, the OS can adjust the MCU frequency to optimize the power consumption. The authors suggest an ARM-based MCU for the OS implementation. However, the implementation of OS in limited resource 8-bit microcontrollers such as the ATMEGA328P will force the MCU to operate at higher frequencies dissipating more energy. Another study by Ling Lin et al.[38] proposed a multipower space fabrication scheme for MCUs to reduce the power consumption during sleep mode, which required a redesign of the MCU.

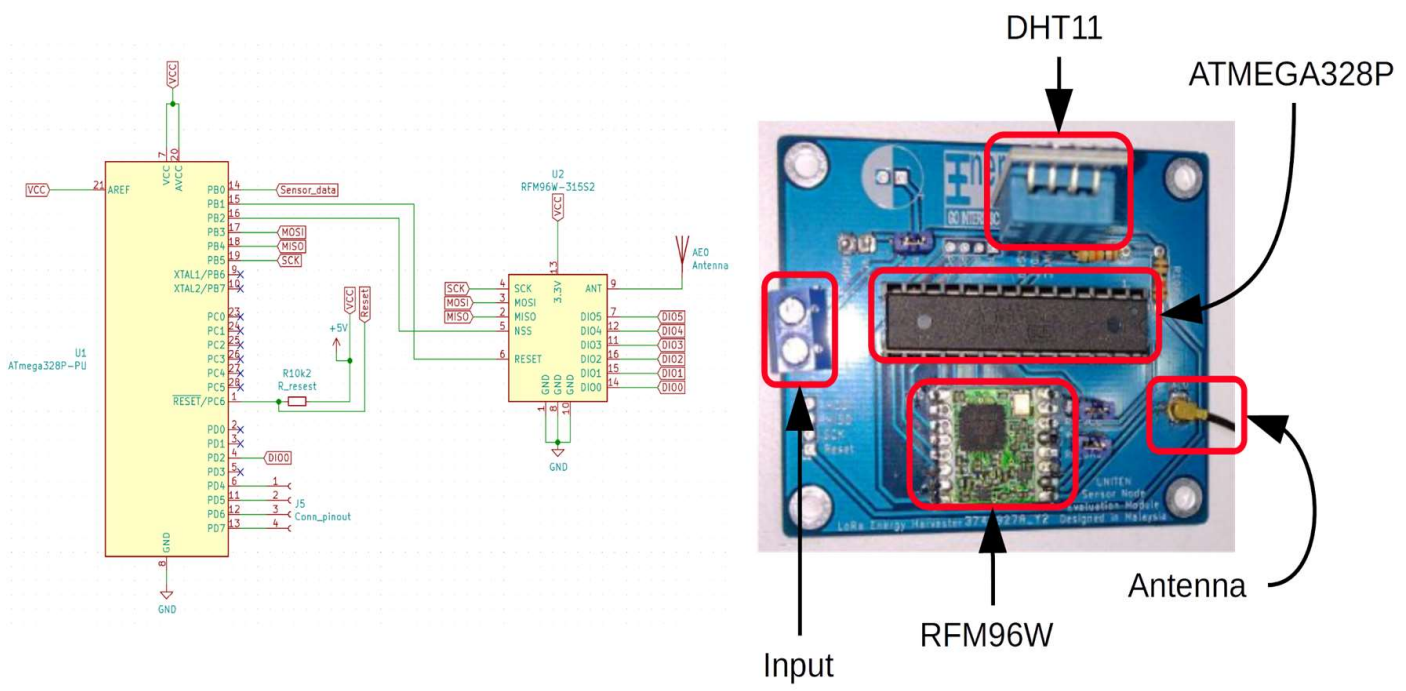

(a)

(b)

Figure 16. The designed WSTx where (a) is the circuit diagram and (b) is the actual design.

Angelo Silva et al.[48] proposed a power gating technique to reduce the power consumption during the sleep mode. Power gating techniques simply disable the power line from all the WSTx elements. The efficiency of this technique highly depends on the type of WSN application. The disadvantage of power gating is the power consumption during the initialization period, which is required upon resting all the WSTx elements. The initialization period is the period needed for the WSTx to define the communication parameters, registers, and connection ports. One important consideration about designing ultralow-power WSN is the type of MCU. Some microcontrollers have a relatively high power consumption under the deep sleep mode [49]. For example, Md. Rokonuzzaman et al [50] proposed a similar self-power WSN device based on an indoor solar harvester. The study used the ESP32 MCU, DHT temperature humidity sensor, moisture sensor, and ADP5091 PMU with a total power consumption of $200 \mathrm{~mW}$, representing a considerable consumption value. The harvested energy lasted for $96 \mathrm{~s}$ via a $0.47 \mathrm{~F}$ supercapacitor.

Table 2. The current and voltage characteristics of the WSTx components. 


\begin{tabular}{|c|c|c|c|c|c|c|}
\hline & \multicolumn{2}{|l|}{ ATMEGA328P } & \multirow{2}{*}{$\begin{array}{c}\text { RFM96W } \\
1.8-3.7\end{array}$} & \multicolumn{3}{|c|}{ DHT11 } \\
\hline $\begin{array}{l}\text { Operating } \\
\text { Voltage (V) }\end{array}$ & $1.8-5.5$ & & & & $3-5.5$ & \\
\hline Current & Active & 0.2 & Sleep & $0.0002-0.001$ & Measuring & $0.5-2.5$ \\
\hline \multirow[t]{7}{*}{ Consmuption(mA) } & Power-down & 0.00010 & Idle & 0.0015 & Average & $0.2-1$ \\
\hline & Power-save & 0.00074 & Standby & $1.6-1.8$ & Standby & $0.01-0.15$ \\
\hline & & & Receive & 11.47 (AVG) & & \\
\hline & & & Transmit & +20 dBm 120 & & \\
\hline & & & & $+\mathbf{1 7} \mathbf{d B m} 87$ & & \\
\hline & & & & +13 dBm 29 & & \\
\hline & & & & $+7 \mathrm{dBm} \quad 20$ & & \\
\hline
\end{tabular}

To reduce the power consumption from the WSTx, we proposed a firmware-based power managing method. The proposed method applies only to digital sensors due to its programmability feature. The method has two stages, the initialization stage and the main program loop stage, as in Figure 18. The initialization is only performed once to avoid high power consumption during the initialization period [51]. The initialization stage consists of three procedures. The first procedure is the MCU initialization which includes the following tasks: disabling the unused devices inside the MCU, such as the Brown-Out Detector (BOD) and the Analog to Digital Converter (ADC), setting the input and output ports, defining the operating frequency, defining the sleep mode, and setting the WatchDog-Timer (WDT). The BOD is the device responsible for distinguishing between high and low voltage levels. However, in such an energy harvesting situation, the low voltage level from the boost charger is always less than the standard BOD logic level. Disabling the BOD will help accept voltages lower than the BOD level as low as $1.8 \mathrm{~V}$, representing the minimum voltage level to operate the MCU and the Lora module. Figure 17 shows the logic voltage levels of the boost charger versus the BOD 2.7 voltage level.

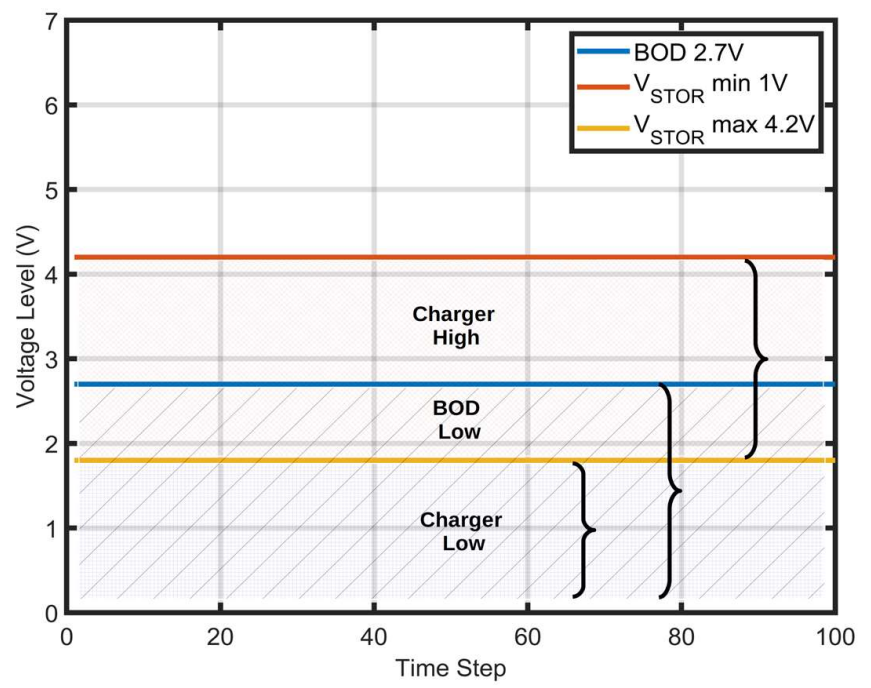

Figure 17. The BOD voltage level versus the charger voltage levels.

The ADC converts the continuous-time signals into digital signals. Usually, the ADC is attached to an analog sensor that measures a physical quantity. However, the analog to digital transformation process consumes more energy; hence a digital sensor can be used to avoid using the ADC. The clock frequency is essential in reducing power consumption, where higher clock rates require more power [51]. The ATMEGA38P has six sleeping modes: idle, ADC noise reduction, power-down, power-save, standby, and extended standby. 


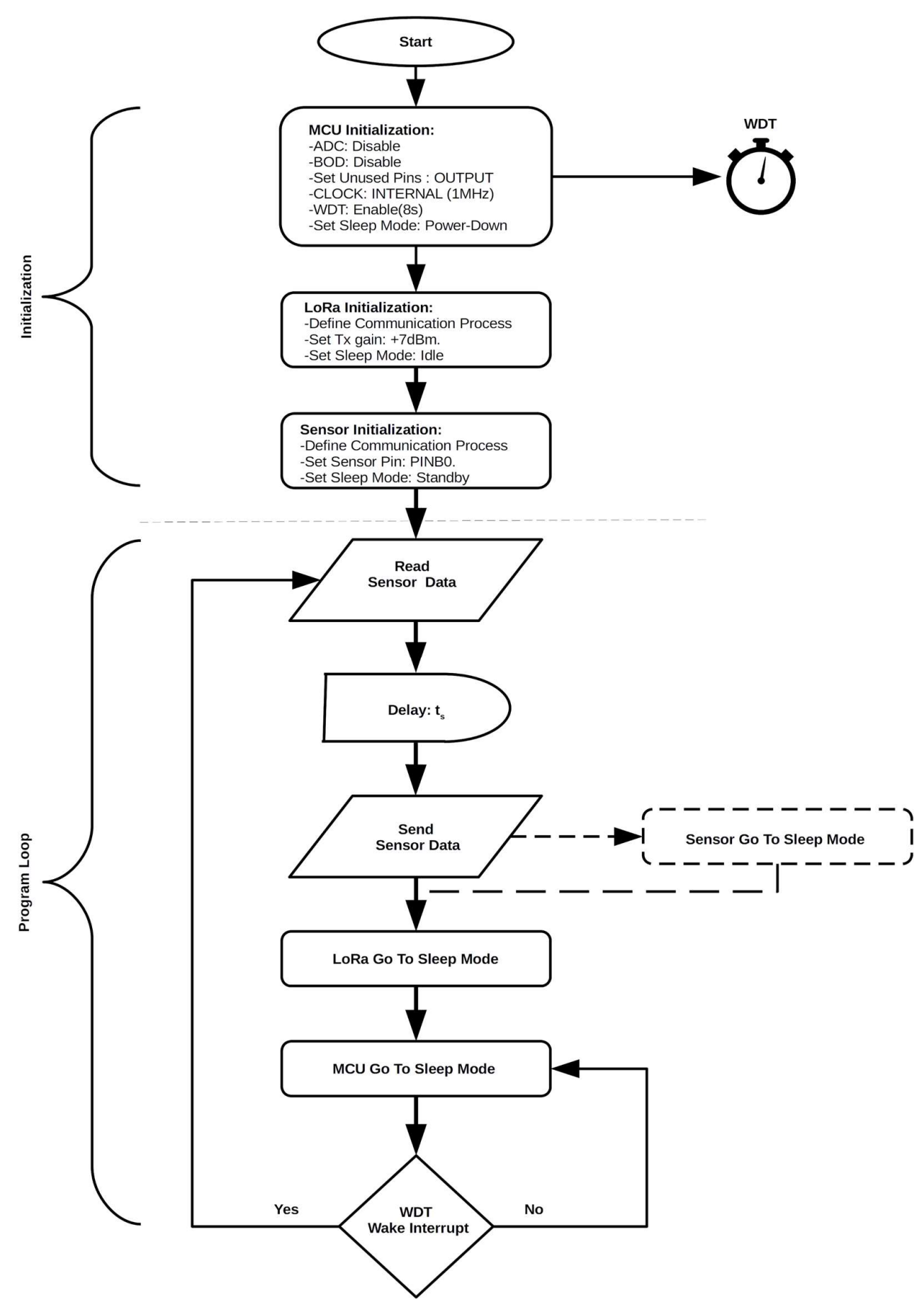

Figure 18. The proposed firmware-based power consumption flowchart.

Figure 19 illustrates the power consumption of the ATMEGA328P sleep modes, where the power down represents the most miniature power consumption mode. The power-down sleep mode halts the system clock where an interrupt signal is required to wake up the processor. Since the WDT is separate from the system clock, it can be used as a system clock independent device to wake up the processor. Therefore, we used the WDT to produce an internal interrupt signal after completing the sleep duration. The WDT has been set to the maximum time-out value of 8 seconds. 


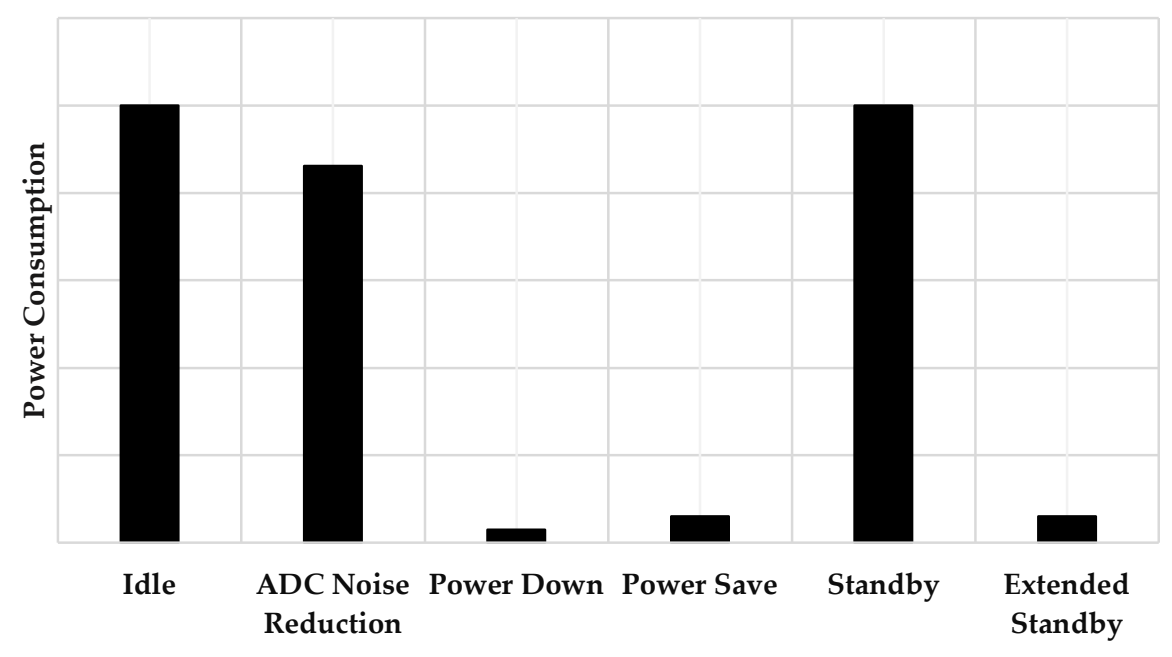

Figure 19. Power consumption of the ATMEGA328P sleep modes.

The second stage of the initialization is of the RFM96 LoRa module. This process aimed to define the LoRa modulation, define the communication parameter, and set the RFM96 sleep mode. The communication between the MCU and the LoRa module is done through the Serial Peripheral Interface (SPI) protocol. The third stage of the initialization is the sensor initialization which consists of setting the sensor pins and defining the sensor communication protocol where the DHT11 uses a half-duplex single-wire serial communication protocol. The sampling rate of the DHT sensor has been set to $1 \mathrm{~Hz}$, which is the maximum sampling frequency of the device; hence a $t_{s}$ delay of 1 second has been added after every reading.

The program loop starts with acquiring the data from the sensor through the singlewire protocol. This process requires an amount of delay $t_{s}$. After the delay period, the MCU will transfer the sensor data to the LoRa module, which will transmit the data to the gate node or any neighbour node. After the transmission process, the LoRa module will go to sleep mode, followed by the MCU. Some digital sensors also can be configured to enable the sleep mode; therefore, more power can be saved during the sleep mode. The WDT will interrupt the MCU after the time-out duration, and the loop will start again from acquiring new data from the sensor.

\section{Results}

This section provides details about the designed ultra-low power WSTx. To develop an efficient energy harvester, the source power $P_{s}$ from the PMU should always be greater than the consumption power $P_{c}$. Therefore, the lower power the consumption at the WSTx, the more efficient the harvesting system. Practically, some amount of power dissipates through the power management and the storing processes, affecting the harvesting system's efficiency. Mathematically, the power consumption can be described as the in (13) where $B_{0}$ is the initial stored energy, $\eta_{c}$ is the charging efficiency, $f$ is the capacity limit function which has been described in (14), Pleak is the capacitance leakage power, and $B$ is the size of the supercapacitor [52].

$$
\begin{gathered}
B_{0}+\eta_{c} \int_{0}^{T} f\left(P_{S}(t)-P_{c}(t)\right) d t-\int_{0}^{T} f\left(P_{c}(t)-P_{S}(t)\right) d t-\int_{0}^{T} P_{\text {leak }}(t) d t \geq B, \quad \forall T \in[0, \infty) \\
f(x)= \begin{cases}x & x \geq 0 \\
0 & x<0\end{cases}
\end{gathered}
$$

The maximum voltage limit of the supercapacitor represents one of the fundamental limitations in the harvesting system, where it will affect the $P_{s}$ side [52]. Also, the supercapacitor has an internal resistance in which self-discharging occurs without the presence 
of load. The self-discharging problem can represent a challenge if there is no input power for a long duration, where the voltage across the supercapacitor should always be greater than $1.8 \mathrm{~V}$. Figure 20 shows the voltage drop across the supercapacitor terminal due to the self-discharging impact.

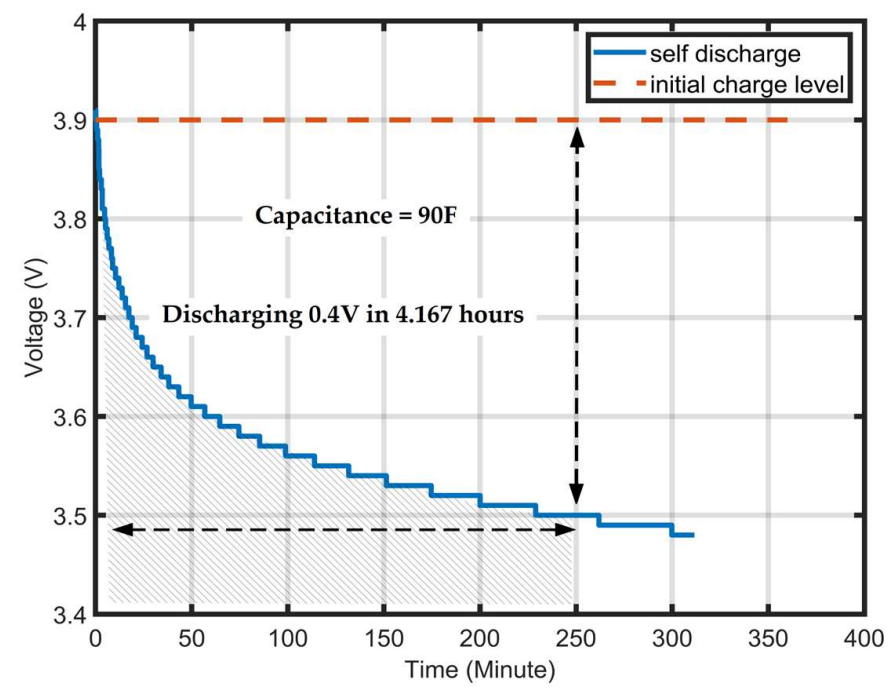

Figure 20. Supercapacitor voltage drop due to self-discharge impact (open-circuit).

The voltage drop can be minimized by increasing the deep sleep duration. However, the WDT of the ATMEGA328P has a maximum time-out duration of 8 seconds. Table 3 shows the results of the proposed firmware-based power reduction technique. In these measurements, the transmission power of the LoRa module has been set to a fixed gain of $7 \mathrm{dbm}$; also, the power consumption has been measured with a fixed input voltage of $3.7 \mathrm{~V}$. The results prove the efficiency of disabling the $\mathrm{ADC}$, reducing the internal clock frequency to $1 \mathrm{MHz}$, and selecting the power-down sleep mode. This technique reduced power consumption during the sleep mode to $21.09 \mu \mathrm{W}$ and $11.1 \mathrm{~mW}$ at the operation mode. Figure 21 shows the current consumption during the initialization, operation, and sleep mode concerning the solar input the boost charger output.

Table 3. Comparison of power consumption with different firmware configurations (at 3.7V, Tx gain $7 \mathrm{dBm}$ )

\begin{tabular}{cccccc}
\hline & $\mu$ C Sleep Mode & $\begin{array}{c}\text { MCU } \\
\text { Internal } \\
\text { Frequency(MHz) }\end{array}$ & $\begin{array}{c}\text { ADC } \\
\text { Consumption }(\mu W) \\
\text { At Operation Mode }\end{array}$ & $\begin{array}{c}\text { Power } \\
\text { Consumption }(\mu W) \\
\text { At Sleep Mode }\end{array}$ \\
\hline Case 1 & Idle & 4 & On & 25900 & 15540 \\
Case 2 & Idle & 2 & On & 22200 & 13283 \\
Case 3 & Idle & 2 & Off & 22090 & 12395 \\
Case 4 & Idle & 1 & Off & 17020 & 9990 \\
Case 5 & Power Save & 1 & Off & 11100 & 83 \\
Case 6 & Power Down & 1 & Off & $\mathbf{1 1 1 0 0}$ & $\mathbf{2 1 . 0 9}$ \\
\hline
\end{tabular}




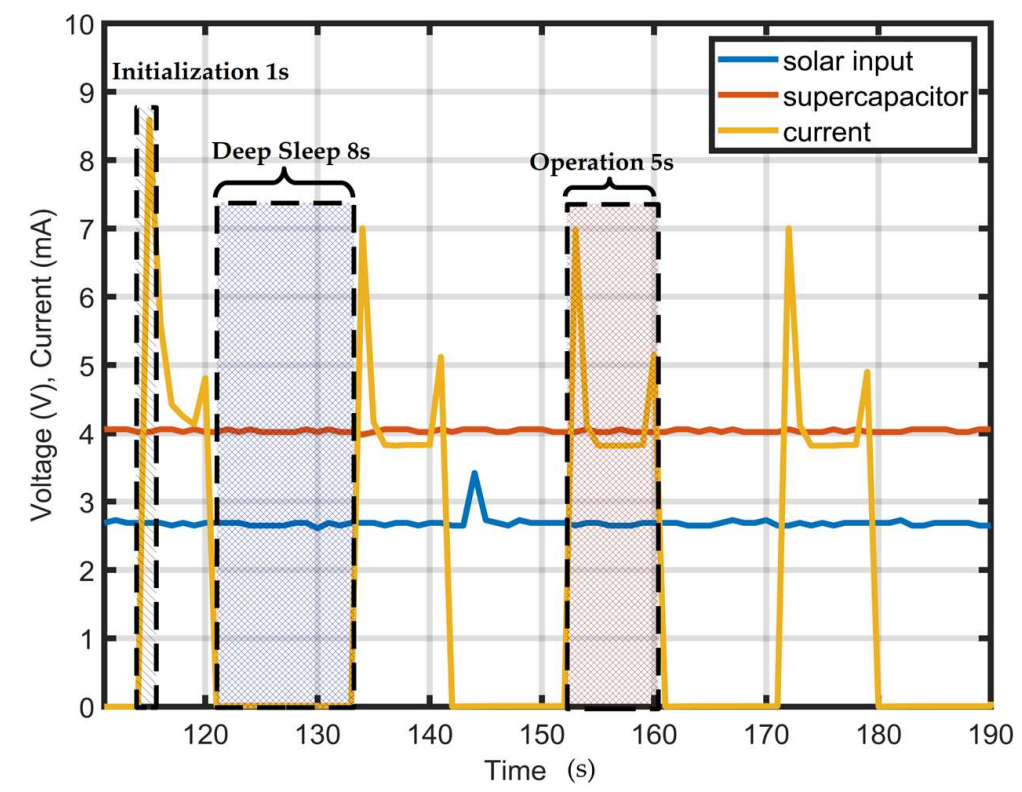

Figure 21. WSTx current consumption during the initialization, operation, and deep sleep mode.

The algebraic summation of the power consumption through the WSTx elements represents the total power consumption $P_{w s t x}$. as in (15). Where $P_{\beta}$ is the power consumption through the Printed Circuit Board (PCB) and the resistors. Figure 22 describes the percentage of the net power consumption of the WSTx component. The energy can be described as the amount of power consumption per time unit (16), where the total energy consumption can be calculated as in (17) [53]. Equation (17) emphasizes the crucial role of sleep duration in reducing the energy where $t_{\text {cycle }}$ describes how frequent the operation cycle is; therefore, increasing the sleep time will decrease the sum of the active durations.

$$
\begin{gathered}
P_{\text {wstx }}=P_{m c u}+P_{\text {sen }}+P_{\text {LoRa }}+P_{\beta} \\
E=I . V . T \\
E_{\text {wstx }}=P_{\text {wstx }} . t_{\text {active }}+P_{\text {wstx(sleep }) .}\left(t_{\text {cycle }}-t_{\text {active }}\right)+E_{\text {wstx }(\text { wake-up })}
\end{gathered}
$$

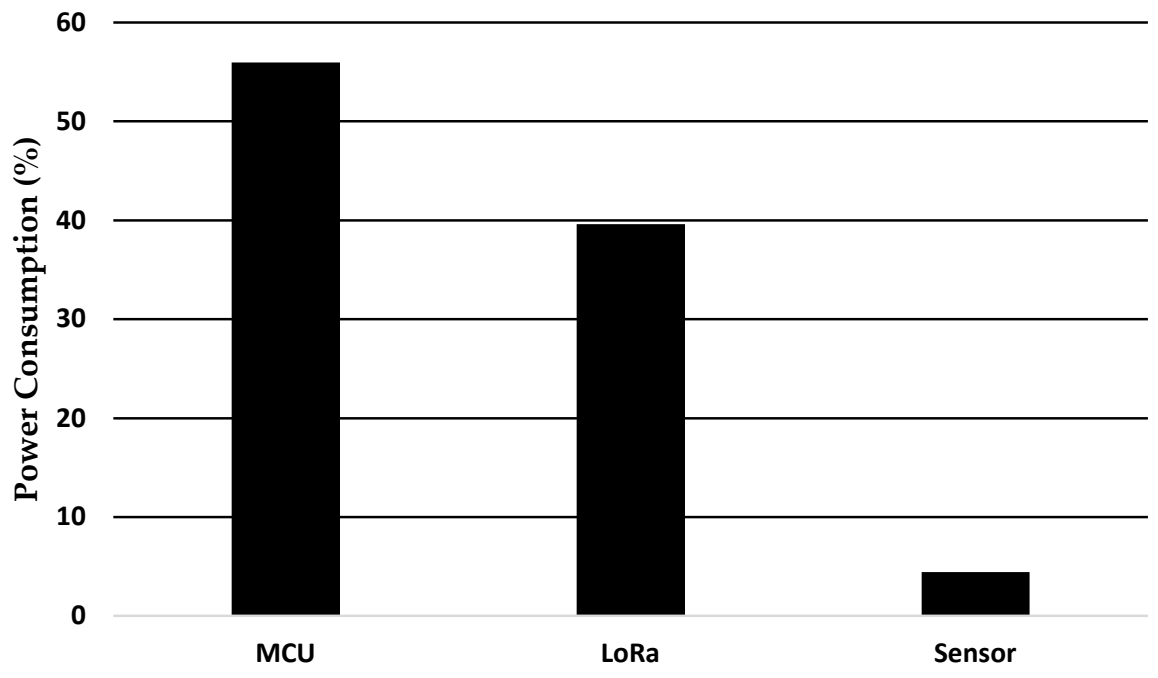

Figure 22. The power consumption percentage of the WSTx elements. 


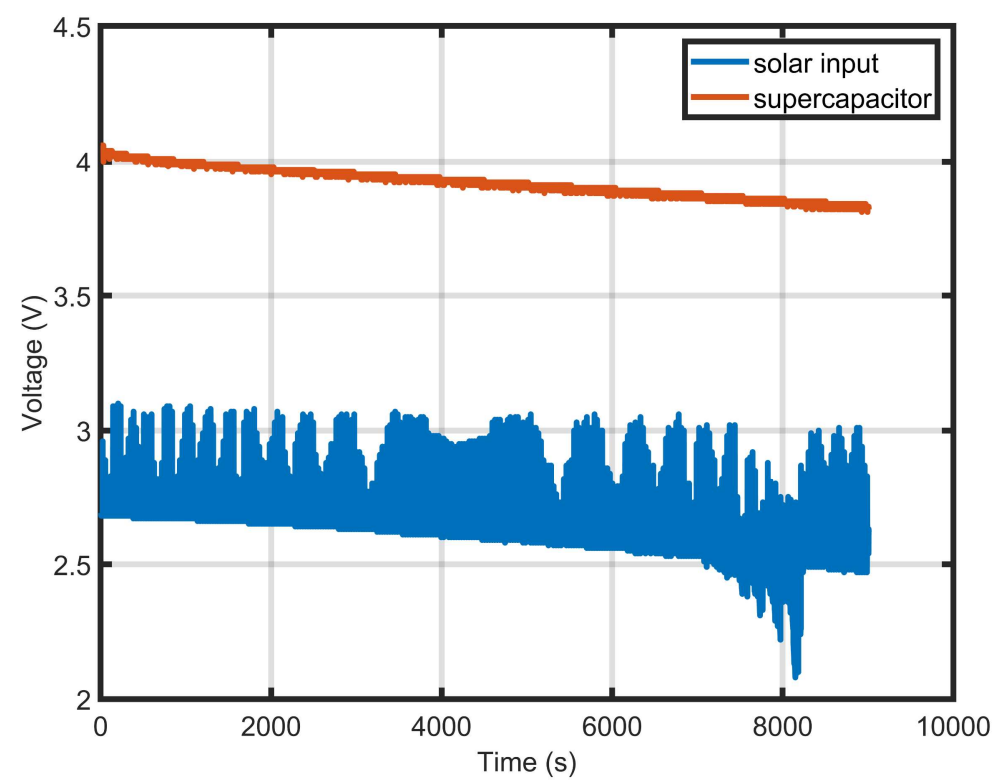

Figure 23. Voltage drop rate during the harvesting (closed-circuit).

The sleep duration should be long enough to allow the solar harvester to compensate for the consumed power. Figure 23 shows the closed-circuit voltage drop across the supercapacitor terminals as an impact of the 8 seconds sleep duration. However, the WDT time-out of 8 seconds is not enough to support the WDTx for a long time where the capacitor charge can last only for continuous 6 hours. The critical deep sleep time can be estimated based on the energy harvesting rate. Figure 24 compares the energy harvesting during the open- and closed-circuit configuration. The closed-circuit harvesting rate can reach a maximum of $1.2 \mathrm{~mW}$ per second; however, the energy harvesting rate declines rapidly due to the imbalance between power consumption and the power source. Therefore at least 12 seconds of deep sleep are required to match the power consumption during the operation mode. The maximum power efficiency $\eta_{W S T X}$ of the WSTx unit can be calculated as in (18). Fortunately, the current revolution in the Lithium-ion capacitor may significantly improve the supercapacitor electrical characteristics [54] by reducing the selfdischarging rate.

$\eta_{W S T x} \%=\frac{\text { Max }_{\text {Pout }}}{M P P_{\text {indoor }}} \times 100 \%=\frac{1.2 \mathrm{~mW}}{1.4 \mathrm{~mW}} \times 100 \%=85.714 \%$

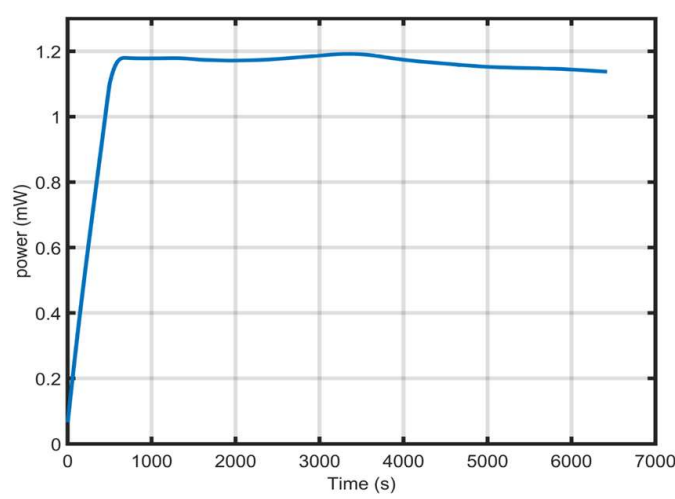

(a)

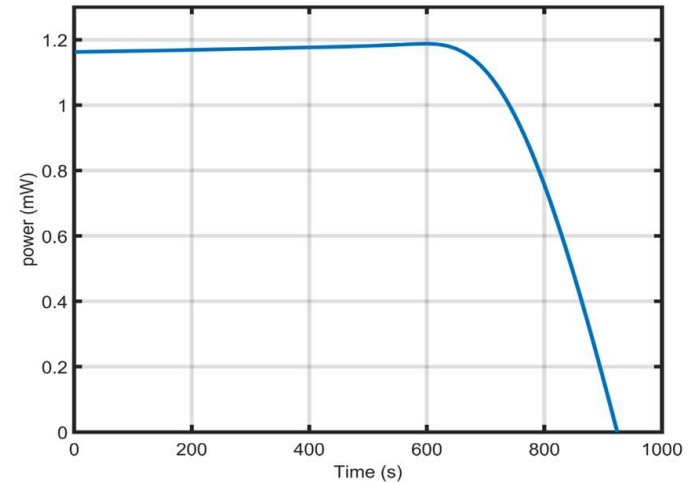

(b)

Figure 24. Energy harvesting profile; where (a) is the open-circuit energy harvesting and (b) is the closed-circuit energy harvesting 


\section{Discussion}

The study shows the ability of the indoor solar harvester to support theWSTx device without depending on any external source of power supply. However, some points that can be addressed by future works are listed below.

- $\quad$ Studying the feasibility of using different types of PV technologies.

- Using different MCUs that has long WDT time-out duration.

- $\quad$ Studying the impact of using Lithium-ion capacitors to improve the self-discharging effect.

\section{Conclusions}

The aim of this paper was to design a low power WSTx unit using indoor solar power harvester and LoRa technologies. A description of the design details and the expected power management limitations have been provided. The results showed a significant improvement had been achieved in the power consumption during the sleep mode with $21.09 \mu \mathrm{W}$ and $11.1 \mathrm{~mW}$ during the operation mode. The stored energy can support the WSTx for a continuous 6 hours. The study demonstrated a potential towards self-powered WSN by utilizing emerging energy harvesting and low power communication technologies. Furthermore, we discussed the efficiency of using polycrystalline photovoltaic PV cells to harvest the ambient indoor light. The PV panels can provide a maximum power of $1.4 \mathrm{~mW}$. The power consumption of the developed WSTx was $21.09 \mu \mathrm{W}$ during the sleep mode and $11.1 \mathrm{~mW}$ during the operation mode, where the harvested energy can support the WSTx for a continuous 6 hours. The harvesting system was able to harvest up to $1.2 \mathrm{~mW}$ per second, Where the designed WSTx achieved a maximum power efficiency of $85.714 \%$.

Author Contributions: Conceptualization, FMEH, AAA; Data curation, FMEH; Formal analysis, AAA, NMD; Funding acquisition, NMD, SNMD; Investigation, AAA, NMD; Methodology, FMEH; Project administration, NMD, SNMD; Resources, NMD and SNMD; Software, FMEH; Supervision, NMD and SNMD; Validation, AAA; Visualization, FMEH; Writing - original draft, FMEH; Writing-review and editing, NMD and AAA. All authors have read and agreed to the published version of the manuscript.

Funding: This research was funded by the Innovation and Research Management Centre (IRMC), Universiti Tenaga National (UNITEN) Malaysia, under the IC6-BOLDREFRESH2025 grant, project code J510050002.

Acknowledgments: The authors expressed their sincere gratitude to all bodies that have provided their insight and expertise in this study, especially The Energy Sphere IoT lab.

Conflicts of Interest: The authors declare no conflict of interest.

\section{Appendix A}
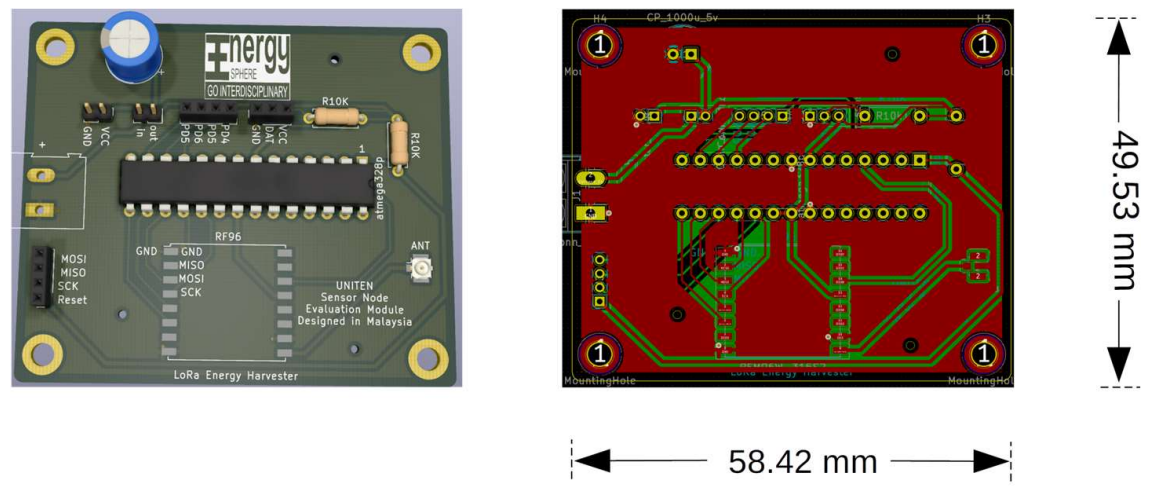

APPENDIX A. The PCB design of the WSTx. 


\section{References}

[1] M. U.Farooq, M. Waseem, S. Mazhar, A. Khairi, and T. Kamal, "A Review on Internet of Things (IoT)," International Journal of Computer Applications, vol. 113, no. 1, pp. 1-7, Mar. 2015, doi: 10.5120/19787-1571.

[2] M. N. Bhuiyan, M. M. Rahman, M. M. Billah, and D. Saha, "Internet of Things (IoT): A Review of Its Enabling Technologies in Healthcare Applications, Standards Protocols, Security, and Market Opportunities," IEEE Internet of Things Journal, vol. 8, no. 13. Institute of Electrical and Electronics Engineers Inc., pp. 10474-10498, Jul. 01, 2021. doi: 10.1109/JIOT.2021.3062630.

[3] H. Ghayvat, S. Mukhopadhyay, X. Gui, and N. Suryadevara, "WSN- and IOT-based smart homes and their extension to smart buildings," Sensors (Switzerland), vol. 15, no. 5, pp. 10350-10379, May 2015, doi: 10.3390/s150510350.

[4] M. T. Lazarescu, "Design of a WSN platform for long-term environmental monitoring for IoT applications," IEEE Journal on Emerging and Selected Topics in Circuits and Systems, vol. 3, no. 1, pp. 45-54, 2013, doi: 10.1109/JETCAS.2013.2243032.

[5] I. F. Akyildiz, W. Su, Y. Sankarasubramaniam, and E. Cayirci, "Wireless sensor networks: A survey," Computer Networks, vol. 38, no. 4, pp. 393-422, Mar. 2002, doi: 10.1016/S1389-1286(01)00302-4.

[6] R. Mahakud et al., "Energy Management in Wireless Sensor Network Using PEGASIS," in Procedia Computer Science, 2016, vol. 92, pp. 207-212. doi: 10.1016/j.procs.2016.07.347.

[7] S. You, J. K. Eshraghian, H. C. Iu, and K. Cho, “Low-power wireless sensor network using fine-grain control of sensor module power mode," Sensors, vol. 21, no. 9, May 2021, doi: 10.3390/s21093198.

[8] M. L. Liya and M. Aswathy, "LoRa technology for Internet of Things(IoT):A brief Survey," in Proceedings of the 4th International Conference on IoT in Social, Mobile, Analytics and Cloud, ISMAC 2020, Oct. 2020, pp. 128-133. doi: 10.1109/I-SMAC49090.2020.9243449.

[9] C. Saad, E. A. Cheikh, B. Mostafa, and H. Abderrahmane, "Comparative Performance Analysis of Wireless Communication Protocols for Intelligent Sensors and Their Applications," 2014. [Online]. Available: www.ijacsa.thesai.org

[10] P. D. P. Adi, A. Kitagawa, D. A. Prasetya, and A. B. Setiawan, "A Performance of ES920LR LoRa for the Internet of Things: A Technology Review," in 3rd 2021 East Indonesia Conference on Computer and Information Technology, EIConCIT 2021, Apr. 2021, pp. 1-7. doi: 10.1109/EIConCIT50028.2021.9431912.

[11] M. L. Liya and M. Aswathy, "LoRa technology for Internet of Things(IoT):A brief Survey," in Proceedings of the 4th International Conference on IoT in Social, Mobile, Analytics and Cloud, ISMAC 2020, Oct. 2020, pp. 128-133. doi: 10.1109/I-SMAC49090.2020.9243449.

[12] M. S. Mahmoud and A. A. H. Mohamad, "A Study of Efficient Power Consumption Wireless Communication Techniques/ Modules for Internet of Things (IoT) Applications," Advances in Internet of Things, vol. 06, no. 02, pp. 19-29, 2016, doi: 10.4236/ait.2016.62002.

[13] R. A. Kjellby et al., "Self-powered IoT Device based on Energy Harvesting for Remote Applications," in International Symposium on Advanced Networks and Telecommunication Systems, ANTS, Jul. 2018, vol. 2018December. doi: 10.1109/ANTS.2018.8710171.

[14] H. He and T. Li, "Design of an indoor RF Energy Harvesting Module using Dual-Band Rectenna Array for IoT Applications," 2019.

[15] N. Garg and R. Garg, "Energy Harvesting in IoT Devices: A Survey," in Proceedings of the International Conference on Intelligent Sustainable Systems (ICISS 2017) : 7-8, December 2017, ISBN:978-1-5386-1959-9, Dec. 2017, pp. 7-8.

[16] B. Li, B. Hou, and G. A. J. Amaratunga, “ Indoor photovoltaics, The Next Big Trend in solution-processed solar cells ," InfoMat, vol. 3, no. 5, pp. 445-459, May 2021, doi: 10.1002/inf2.12180. 
[17] G. dos Santos Oliveira, E. P. de Oliveira, A. P. da Silva, and C. C. M. de Moura Carvalho, "Power quality of LED lamps," in Proceedings of International Conference on Harmonics and Quality of Power, ICHQP, Dec. 2016, vol. 2016December, pp. 575-580. doi: 10.1109/ICHQP.2016.7783359.

[18] A. K. Nair, Arunraj, N. Kumar, J. C. Ramya, and V. Kirubakaran, "Performance analysis of LED and florescent lamps a case study of street lightning system," in 2016 International Conference on Energy Efficient Technologies for Sustainability, ICEETS 2016, Oct. 2016, pp. 850-855. doi: 10.1109/ICEETS.2016.7583865.

[19] J. Tan, K. Yang, M. Xia, and Y. Yang, "Analysis of uniform illumination system with imperfect Lambertian LEDs," 2011.

[20] D. Wu, Z. Ghassemlooy, H. le Minh, S. Rajbhandari, and M. A. Khalighi, “Optimization of Lambertian order for indoor non-directed optical wireless communication," in 2012 1st IEEE International Conference on Communications in China Workshops, ICCC 2012, 2012, pp. 43-48. doi: 10.1109/ICCCW.2012.6316472.

[21] S. Song, I. Elgezua, Y. Kobayashi, and M. G. Fujie, "Study on method to simulate light propagation on tissue with characteristics of radial-beam LED based on Monte-carlo method," in Proceedings of the Annual International Conference of the IEEE Engineering in Medicine and Biology Society, EMBS, 2013, pp. 25-28. doi: 10.1109/EMBC.2013.6609428.

[22] K. N. Afonin et al., "LED lamp design optimizing on minimum non-uniformity of light intensity distribution in space," in 2016 13th International Scientific-Technical Conference on Actual Problems of Electronic Instrument Engineering, APEIE 2016 - Proceedings, Jul. 2016, vol. 2, pp. 153-155. doi: 10.1109/APEIE.2016.7806435.

[23] Y. Xu, Y. Chang, G. Chen, and H. Lin, “The research on LED supplementary lighting system for plants," Optik, vol. 127, no. 18, pp. 7193-7201, Sep. 2016, doi: 10.1016/j.ijleo.2016.05.056.

[24] H. Nasim and Y. Jamil, “Diode lasers: From laboratory to industry," Optics and Laser Technology, vol. 56. pp. 211222, 2014. doi: 10.1016/j.optlastec.2013.08.012.

[25] P. K. Nayak, S. Mahesh, H. J. Snaith, and D. Cahen, "Photovoltaic solar cell technologies: analyzing the state of the art," Nature Reviews Materials, vol. 4, no. 4, pp. 269-285, Apr. 2019, doi: 10.1038/s41578-019-0097-0.

[26] M. v. Dambhare, B. Butey, and S. v. Moharil, "Solar photovoltaic technology: A review of different types of solar cells and its future trends," in Journal of Physics: Conference Series, Jun. 2021, vol. 1913, no. 1. doi: 10.1088/17426596/1913/1/012053.

[27] M. Mirzaei and M. Z. Mohiabadi, "A comparative analysis of long-term field test of monocrystalline and polycrystalline PV power generation in semi-arid climate conditions," Energy for Sustainable Development, vol. 38, pp. 93-101, Jun. 2017, doi: 10.1016/j.esd.2017.01.002.

[28] C. E. C. Nogueira, J. Bedin, R. K. Niedzialkoski, S. N. M. de Souza, and J. C. M. das Neves, "Performance of monocrystalline and polycrystalline solar panels in a water pumping system in Brazil," Renewable and Sustainable Energy Reviews, vol. 51. Elsevier Ltd, pp. 1610-1616, Aug. 04, 2015. doi: 10.1016/j.rser.2015.07.082.

[29] M. H. Ann et al., "Device design rules and operation principles of high-power perovskite solar cells for indoor applications," Nano Energy, vol. 68, Feb. 2020, doi: 10.1016/j.nanoen.2019.104321.

[30] Y. Zhang et al., "Comparative indoor and outdoor stability measurements of polymer based solar cells," Scientific Reports, vol. 7, no. 1, Dec. 2017, doi: 10.1038/s41598-017-01505-w.

[31] S. Biswas and H. Kim, "Solar cells for indoor applications: Progress and development," Polymers, vol. 12, no. 6, p. 1338, Jun. 2020, doi: 10.3390/POLYM12061338.

[32] R. TAMRAKAR and A. GUPTA, “A Review extraction of solar cell modelling parameters," IJIREEICE, pp. 5560, Jan. 2015, doi: 10.17148/ijireeice.2015.3111. 
[33] G. Apostolou, A. Reinders, and M. Verwaal, "Comparison of the indoor performance of 12 commercial PV products by a simple model," Energy Science and Engineering, vol. 4, no. 1, pp. 69-85, Jan. 2016, doi: 10.1002/ese3.110.

[34] S. Bader, X. Ma, and B. Oelmann, "One-diode photovoltaic model parameters at indoor illumination levels - A comparison," Solar Energy, vol. 180. Elsevier Ltd, pp. 707-716, Mar. 01, 2019. doi: 10.1016/j.solener.2019.01.048.

[35] P. R. Michael, D. E. Johnston, and W. Moreno, "A conversion guide: Solar irradiance and lux illuminance," Journal of Measurements in Engineering, vol. 8, no. 4, pp. 153-166, 2020, doi: 10.21595/jme.2020.21667.

[36] H. Jayakumar, A. Raha, Y. Kim, S. Sutar, W. S. Lee, and V. Raghunathan, “Energy-efficient system design for IoT devices," in Proceedings of the Asia and South Pacific Design Automation Conference, ASP-DAC, Mar. 2016, vol. 25-28-January-2016, pp. 298-301. doi: 10.1109/ASPDAC.2016.7428027.

[37] M. Abdelaal and O. Theel, "Power Management in Wireless Sensor Networks: Challenges and Solutions."

[38] L. Lin, Z. Tang, N. Tan, and X. Xiao, "Power management in low-power MCUs for energy IoT applications," Journal of Sensors, vol. 2020, 2020, doi: 10.1155/2020/8819236.

[39] “BQ25570EVM-206 Evaluation board I TI.com." https://www.ti.com/tool/BQ25570EVM-206 (accessed Dec. 25, 2021).

[40] S. Kim and P. H. Chou, "Energy harvesting: Energy harvesting with supercapacitor-based energy storage," in Smart Sensors and Systems, Springer International Publishing, 2015, pp. 215-241. doi: 10.1007/978-3-319-147116_10.

[41] A. du Pasquier, I. Plitz, S. Menocal, and G. Amatucci, "A comparative study of Li-ion battery, supercapacitor and nonaqueous asymmetric hybrid devices for automotive applications," Journal of Power Sources, vol. 115, no. 1, pp. 171-178, Mar. 2003, doi: 10.1016/S0378-7753(02)00718-8.

[42] P. Mars and C. v Scap, "Coupling a supercapacitor with a small energy-harvesting source SuperCapaCitorS Store energy and deliver peak power in Support of energy har-veSterS. deSignerS Should ConSider Several key iSSueS when pairing them with Small energy-harveSting SourCeS." [Online]. Available: www.edn.com

[43] P. Mars and XX-CAP, “Using supercapacitors in energy harvesting,” 2017. Accessed: Dec. 27, 2021. [Online]. Available: https://www.powersystemsdesign.com/using-supercapacitors-in-energy-harvesting/31

[44] N. Devillers, S. Jemei, M. C. Péra, D. Bienaimé, and F. Gustin, "Review of characterization methods for supercapacitor modelling," Journal of Power Sources, vol. 246, pp. 596-608, 2014, doi: 10.1016/j.jpowsour.2013.07.116.

[45] "ATmega328P | Microchip Technology." https://www.microchip.com/en-us/product/ATmega328P\#documenttable (accessed Dec. 27, 2021).

[46] "RFM96 433/470Mhz RF Transceiver Module, Long Range Wireless Transceiver module _LoRa long range Transceiver module I hoperf." https://www.hoperf.com/modules/lora/RFM96.html (accessed Dec. 27, 2021).

[47] A. Sinha and A. Chandrakasan, "Dynamic power management in wireless sensor networks," IEEE Design and Test of Computers, vol. 18, no. 2, pp. 62-74, Mar. 2001, doi: 10.1109/54.914626.

[48] A. Silva, M. Liu, and M. Moghaddam, "Power-management techniques for wireless sensor networks and similar low-power communication devices based on nonrechargeable batteries," Journal of Computer Networks and Communications, 2012, doi: 10.1155/2012/757291.

[49] M. K. Stojčev, M. R. Kosanović, and L. R. Golubović, "Power management and energy harvesting techniques for wireless sensor nodes," in 9th International Conference on Telecommunications in Modern Satellite, Cable, and Broadcasting Services, TELSIKS 2009 - Proceedings of Paper, Dec. 2009, pp. 65-72. doi: 10.1109/TELSKS.2009.5339410. 
[50] M. D. Rokonuzzaman et al., "Self-sustained autonomous wireless sensor network with integrated solar photovoltaic system for internet of smart home-building (Ioshb) applications," Micromachines, vol. 12, no. 6, Jun. 2021, doi: 10.3390/mi12060653.

[51] A. Wang, Ó. Mathúna, S. Cian, W. S. Wang, N. Wang, and M. Hayes, “Title Practical wireless sensor networks power consumption metrics for building energy management applications Practical Wireless Sensor Networks Power Consumption Metrics for Building Energy Management Applications," 2011. [Online]. Available: http://zuse.ucc.ie/forumbau2011/

[52] A. Kansal, J. Hsu, S. Zahedi, and M. B. Srivastava, "Power Management in Energy Harvesting Sensor Networks," ACM Transactions on Embedded Computing Systems, vol. 6, no. 4, p. 32, 2007, doi: 10.1145/1274858.1274870.

[53] M. Lueders et al., "Architectural and circuit design techniques for power management of ultra-low-power MCU systems," IEEE Transactions on Very Large Scale Integration (VLSI) Systems, vol. 22, no. 11, pp. 2287-2296, Nov. 2014, doi: 10.1109/TVLSI.2013.2290083.

[54] J. J. Lamb and O. S. Burheim, “Lithium-ion capacitors: A review of design and active materials," Energies, vol. 14, no. 4. MDPI AG, Feb. 02, 2021. doi: 10.3390/en14040979. 